\title{
Heart-lung transplantation for patients under 10 with cystic fibrosis
}

\author{
I M Balfour-Lynn, I Martin, B F Whitehead, P G Rees, M J Elliott, M R de Leval
}

\begin{abstract}
The outcome of patients with cystic fibrosis aged under 10 years referred for heartlung transplantation assessment $(n=58)$ was determined and compared with older children $(n=109)$. Similar proportions were placed on to the active waiting list $(64 \% v 71 \%)$ and received transplants $(35 \% v 31 \%)$. Three year posttransplantation survival figures were also similar $(41 \% v 46 \%)$, as were the figures for overall survival for those placed on to the active list (27\% $v 29 \%)$. Paediatricians should not be deterred from referring younger patients for transplantation. (Arch Dis Child 1997;76:38-40)
\end{abstract}

Keywords: cystic fibrosis; heart-lung transplantation; younger children.

Lung transplantation remains the final therapeutic option for end stage lung disease in cystic fibrosis. However, it is often perceived that transplantation is not a viable option for younger children because of difficulties in obtaining suitably sized donor organs. In addition, previous reports have indicated that young children do less well after a transplantation. Accordingly we assessed the outcome of children with cystic fibrosis aged less than 10 years who had been referred for transplantation assessment and compared this with older children.

Transplant Unit, Great Ormond Street Hospital for Children

NHS Trust, Great Ormond Street, London WC1N 3JH

I M Balfour-Lynn

I Martin

B F Whitehead

P G Rees

M J Elliott

$M$ R de Leval

Correspondence to: Dr Balfour-Lynn.

Accepted 2 September 1996 eligible for transplantation from that time, or the provisional waiting list, indicating that they are not severely enough affected but will be reassessed. Reassessments are performed to monitor the rate of decline in the patient's clinical condition in order to decide when placement on to the active list is appropriate. These tend to occur at six monthly intervals although the patient may be seen sooner if requested by the local cystic fibrosis team. Our perioperative management and follow up has been described previously. ${ }^{2}$

Statistical analysis was performed using Minitab software (Minitab Inc, State College, PA, USA). The Mann-Whitney test was used to compare ages and weight centiles in the different groups, and values of $\mathrm{p}<0.05$ were considered significant. Actuarial survival was calculated using standard Kaplan-Meier methodology.

\section{Results}

We assessed 58 patients ( 25 boys, 33 girls) aged 3.5 to 9.9 (median 8.0 ) years, representing $35 \%$ of all children referred with cystic fibrosis (a total of 167). Twenty three (40\%) were immediately placed on to the active waiting list and $29(50 \%)$ were placed on to the provisional waiting list. There was no difference in age or weight centiles between these two groups. Children on the active list had a mean (95\% confidence interval (CI)) forced expiratory volume in one second as percentage predicted for sex and height of $24.4 \%$ (20.9 to 27.9) and mean $(95 \% \mathrm{CI})$ resting oxygen saturation of $85.0 \%$ (82.4 to 87.5$)$. Six patients were not accepted on to either list for reasons including family refusal, previous chest surgery, liver cirrhosis, and being either too sick or too healthy. After reassessments, a total of 37 (64\%) children had been placed on to the active list and $15(26 \%)$ remained on the provisional list (table 1, fig 1).

Twelve patients on the provisional list are still undergoing reassessments, and three have died of respiratory failure after unpredictable precipitous deterioration of their lung disease. Four of the six not accepted have died. Twenty (54\%) children died while waiting for a transplant-median time on the active list before death was 3 (range 0.5-18) months. All deaths were due to respiratory failure secondary to cystic fibrosis lung disease. Four children are still waiting for suitable donor organs.

Of the 37 children on the active list, 13 $(35 \%)$ were given transplants at a median age of 8.9 years (range 5-11 years). Twelve received a heart-lung transplant and one
No (\%) placed on active list

No (\%) given transplants

Post-transplantation survival at three years (\%)

\begin{tabular}{|c|c|c|c|}
\hline \multicolumn{4}{|l|}{$\begin{array}{l}\text { Methods } \\
\text { We conduc } \\
\text { dren with } \\
\text { since our t } \\
\text { March } 198 \\
\text { Children } \\
\text { ised datab } \\
10 \text { were r } \\
\text { sessment } \\
\text { described. } \\
1991 \text { repor } \\
\text { on a day c } \\
\text { surgery is } \\
\text { tion for tra } \\
\text { programm } \\
\text { the active } \\
\text { tes for the two }\end{array}$} \\
\hline \\
\hline & $\begin{array}{l}\text { We conduc } \\
\text { dren with } \\
\text { since our t } \\
\text { March } 198 \\
\text { Children } \\
\text { ised datab } \\
10 \text { were r } \\
\text { sessment } \\
\text { described. } \\
1991 \text { repo } \\
\text { on a day c } \\
\text { surgery is } \\
\text { tion for tr } \\
\text { programm } \\
\text { the active } \\
\text { nes for the two }\end{array}$ & & \\
\hline
\end{tabular}




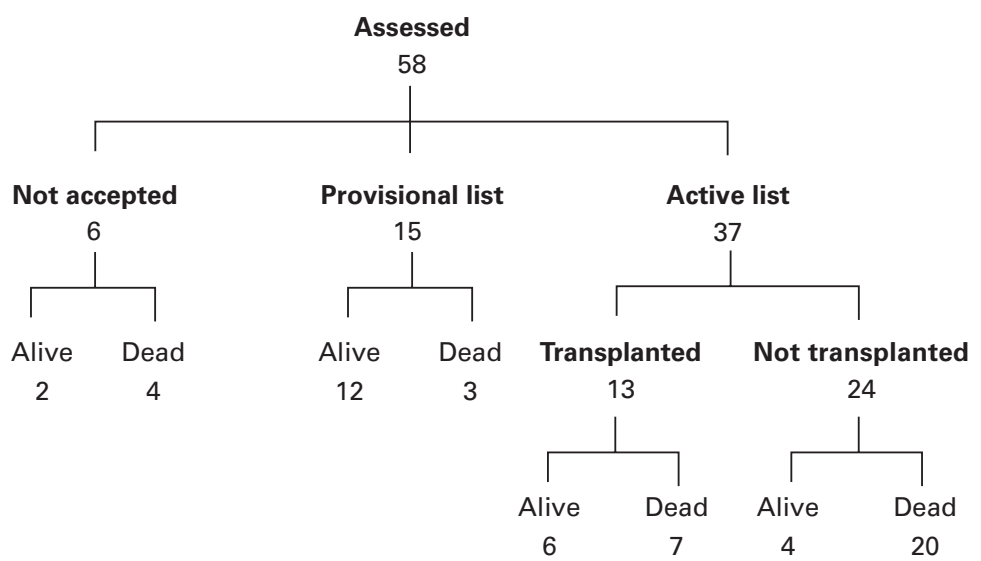

Figure 1 Assessment outcome for children aged under 10 years.

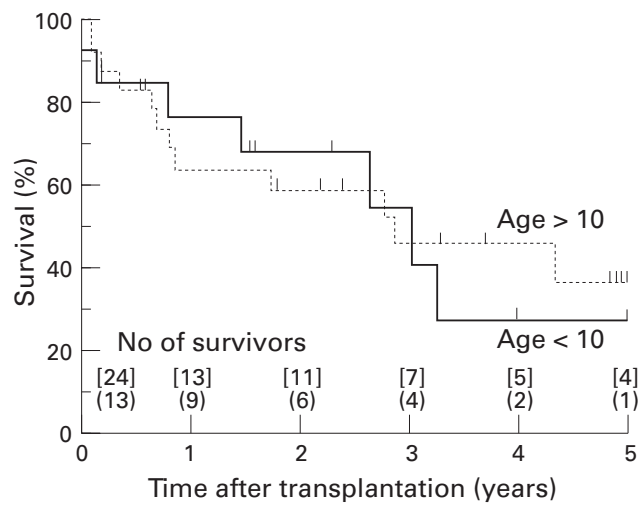

Figure 2 Actuarial survival (\%) after transplantation of children under 10 years (solid line) and over 10 years (dotted line). Tick marks represent survival time since transplantation in patients still alive. Number of survivors at each year is indicated in parentheses (under 10 years old) or square brackets (over 10 years old).

patient a single lung only because of a previous pneumonectomy. Median time waiting was 8 (range 1-22) months. Seven patients died after the transplantation, one from primary graft failure at two days, and all the others from respiratory failure secondary to obliterative bronchiolitis at 2-39 (median 24) months after the transplantation. Actuarial survival (95\% CI) was $76 \%$ (52 to 100 ) at one year, $68 \%$ (42 to 94 ) at two years, and $41 \%$ (8 to 74 ) at three years after the transplantation (fig 2). The six children still alive are all free from obliterative bronchiolitis at 2-77 (median 23) months after the transplantation. One child has a mild resolving hemiparesis, one is partially deaf, and the rest are free from other medical complications. Overall, $27 \%$ of those placed on to the active list are alive.

Review of children over 10 years showed similar results (table 1). We assessed 109 children (median 12.9 years, range 10-21 years) of whom $77(71 \%)$ were accepted on to the active list. Twenty four (31\%) were given transplants at a median age of 14.1 (range 10-19) years. Actuarial survival (95\% CI) was 63\% (39 to 87 ) at one year, $59 \%$ (38 to 80 ) at two years, and $46 \%$ (20 to 69$)$ at three years after the transplantation (fig 2). Deaths were due to obliterative bronchiolitis $(n=11)$, sepsis $(n=2)$, and cerebral infarction after mycotic pseudoaneurysm of the aorta $(n=1)$. Of the 10 patients still alive, at 2-84 (median 28) months after the transplantation, only three are free from obliterative bronchiolitis. Overall survival for those placed on to the active list was $29 \%$.

\section{Discussion}

We have found that children with cystic fibrosis under 10 years of age are at no disadvantage compared with older children in terms of outcome of heart-lung transplantation. The proportion of assessed patients placed on to the active list, the proportion who receive a transplant and post-transplantation survival are all similar. Within the current limits of heart-lung transplantation, it remains a viable option for young children with end stage cystic fibrosis lung disease. Despite concerns that have been expressed over the whole transplantation process, ${ }^{3}$ we would still encourage paediatricians to consider this option. Most transplant survivors have a vastly improved quality of life, even though this may be for a limited period. It is important that the children, their families, and their doctors are realistic over the likely outcome however.

Development of obliterative bronchiolitis after transplantation is a serious problem and it remains the main complication and commonest cause of death in our patients. However, unlike the Harefield series in which it appeared to be commoner in children under 8 years of age, ${ }^{4}$ we have found no age relationship in our own patients. ${ }^{5}$ The reasons for this are not clear but it may be related to the different immunosuppression regimens. In addition, our long term survival figures are no worse for the younger patients. However, until the cause of obliterative bronchiolitis is known, prevention is not possible and currently retransplantation is the only therapeutic option. Eradicating obliterative bronchiolitis will be necessary before survival figures can be dramatically improved.

Lack of donor organs still remains the largest hindrance to any heart-lung transplantation programme. This is particularly true in the paediatric population, where the lungs are often adversely affected by the time organ donation is considered. More than half the patients on our active list died waiting and it is important that appropriate terminal care (from the local cystic fibrosis team or hospice) is not withheld from a dying child in case suitable organs suddenly become available. The median time to death on the active list was short, only three months, which brings into question whether earlier referral and placement on to the active list may have been warranted for some children. Parents often express this concern, particularly if their child is placed on to the provisional list. However, once on the active list, the transplant may happen the next day, so children should not be placed on this list unless definitely indicated. Current schemes to improve organ availability include increasing public awareness and the Department of Health and Royal College of Surgeons initiative to set up donor retrieval teams. ${ }^{6}$ In the future, greater use of living related donors 
and even xenotransplantation may have a major impact on paediatric heart-lung transplantation. ${ }^{6}$

We would like to thank other members of the transplant team at Great Ormond Street Hospital for Children, namely: Pauline Whitmore, Mary Goodwin, Esther Serrano-Ikkos, and Bryan Lask.

1 Whitehead B, Helms P, Goodwin M, et al. Heart-lung transplantation for cystic fibrosis. I: Assessment. Arch Dis Child 1991;66:1018-21. 2 Whitehead BF, Rees PG, Sorensen K, Bull C, Fabre J, de
Leval MR, Elliott MJ. Results of heart-lung transplantation in children with cystic fibrosis. Eur $\mathcal{F}$ Cardiothorac Surg 1995;9:1-6.

3 Warner JO. Heart-lung transplantation: all the facts. Arch Dis Child 1991;66:1013-7.

4 Radley-Smith RC, Burke M, Pomerance A, Yacoub MH. Graft vessel disease and obliterative bronchiolitis after heart/lung transplantation in children. Transplant Proc 1995;27:2017-8.

5 Whitehead B, Rees P, Sorensen K, et al. Incidence of obliterative bronchiolitis after heart-lung transplantation in children. F Heart Lung Transplant 1994;13:903-8.

6 Whitehead BF, de Leval MR. Paediatric lung transplantation: the agony and the ecstasy. Thorax 1994;49: 437-9. 